\title{
POR UMA AGENDA DE PESQUISA SOBRE INGLÊS COMO MEIO DE INSTRUÇÃO NO CONTEXTO DE ENSINO SUPERIOR BRASILEIRO
}

\author{
TOWARD AN EMI RESEARCH AGENDA FOR BRAZILIAN HIGHER EDUCATION
}

\author{
Telma Gimenez* \\ Luciana Cabrini Simões Calvo** \\ Michele Sales El Kadri ${ }^{* *}$ \\ Marilice Zavagli Marson ${ }^{* * * *}$ \\ Atef El Kadri ${ }^{* * * *}$
}

\section{RESUMO}

Este artigo objetiva identificar as tendências dos estudos sobre o Inglês como meio de instrução (IMI) no Brasil e sugerir uma agenda de pesquisa que trate de questões ligadas à sua adoção como uma das línguas empregadas no ensino superior, com vistas à internacionalização. A fim de conhecer como o IMI tem sido abordado em publicações brasileiras, realizamos esta metassíntese qualitativa (MATHEUS, 2009), compreendendo estudos publicados entre 2010 e 2020. Em termos de desenho, os trabalhos foram classificados de acordo com seu caráter: exploratório, descritivo ou explicativo-especulativo (GIL, 2019). As abordagens desses estudos foram categorizadas como de reconfiguração, caso indicassem viés crítico, ou de acomodação, quando estes propunham apenas aperfeiçoamentos na política de IMI (PARK; WEE, 2012). Após análise de conteúdo dos textos, os resultados apontam que as pesquisas exploratórias se sobressaem em relação às outras perspectivas e há maior número de estudos voltados para reconfiguração, sinalizando que a comunidade acadêmica tem questionado e problematizado o IMI no contexto brasileiro, utilizando diferentes vertentes para tal, como a do inglês como língua franca; a decolonialidade; a perspectiva multimodal; a internacionalização crítica, dentre outras.

Palavras-chave: inglês como meio de instrução; pesquisa; metassíntese.

\section{ABSTRACT}

This article aims to identify trends in studies on English as a medium of instruction (EMI) in Brazil and suggest a research agenda that addresses issues related to the adoption of English as one of the languages used in higher education, with a view to internationalization. In order to know how EMI has been addressed in Brazilian publications, we conducted a qualitative meta synthesis (MATHEUS, 2009), comprising studies published between 2010 and 2020. In terms of design, the studies were classified as exploratory, descriptive or explanatory-speculative (GIL, 2019). The studies were classified as within a reconfiguration approach, if they indicated critical bias, or accommodation, when they proposed only improvements in the EMI policy (PARK, WEE, 2012). After content analysis of the texts, the results reveal that exploratory research stands out in relation to other perspectives and there is a higher number of studies within a reconfiguration approach, indicating that the academic community has questioned and problematized EMI in the Brazilian context, using different perspectives for this purpose, such as English as a lingua franca; decolonial studies; multimodal perspective; critical internationalization, among others.

Keywords: English as a medium of instruction; research; meta synthesis.

\section{INTRODUÇÃO}

Estudo recente revelou que universidades brasileiras estão incorporando a oferta de aulas em inglês como parte de suas estratégias de internacionalização (GIMENEZ et al., 2018). Em outros países, as iniciativas e as pesquisas sobre esse contexto linguístico têm se intensificado nas últimas décadas, com inúmeras publicações em periódicos e coletâneas (e.g. BOWLES; MURPHY, 2020; DOIZ; LASAGABASTER; SIERRA, 2013; GALLOWAY, 2020; GALLOWAY; KRIUKOW; NUMAJIRI, 2017; MURATA, 2018; ROBERTS et. al., 2019).

\footnotetext{
* Universidade Estadual de Londrina (UEL), Londrina, PR, Brasil. tgimenez@uel.br. Orcid: https://orcid.org/0000-0001-6143-3895

Bolsista do CNPq - Brasil (Proc. 311655/2018-1).

** Universidade Estadual de Maringá (UEM), Maringá, PR. cabrinisimoes@gmail.com. Orcid: https://orcid.org/0000-0001-8145-0588

***Universidade Estadual de Londrina (UEL), Londrina, PR, Brasil.misalles27@gmail.com. Orcid: https://orcid.org/0000-0002-5836-4988

**** Universidade Estadual de Londrina (UEL), Londrina, PR, Brasil. marilicemarson@gmail.com. Orcid: https://orcid.org/0000-0001-9805-3001

***** Universidade Estadual de Londrina (UEL), Londrina, PR, Brasil. atefelkadri@gmail.com.
} 
Esse interesse levou à criação de uma rede sobre inglês como meio de instrução - tradução de English as a Medium of Instruction ou English Medium Instruction (EMI) - que congrega pesquisadores de diversas partes do mundo (https://www.globalenglishes-emi.education.ed.ac.uk/emi/). Conforme explicam seus coordenadores,

a rede responde à escassez de pesquisas examinando o que está acontecendo no nível prático, a necessidade de materiais e de maior colaboração entre especialistas em conteúdo e linguagem. Ao explorar como os objetivos da política governamental estão sendo operacionalizados no nível institucional e de sala de aula, pretendemos melhorar a qualidade da oferta. A implementação bem-sucedida da política de EMI requer um planejamento cuidadoso para evitar expectativas irrealistas e frustrações. ${ }^{1}$

Em nosso país, também a colaboração tem sido a tônica de pesquisadores interessados em compreender as motivações, as práticas e os impactos da adoção do inglês como língua do ensino superior nas diversas áreas do conhecimento. Um grupo na rede social Facebook intitulado EMI - English Medium Instruction in Brazil (https:// www.facebook.com/groups/1656829521271989), com 200 membros, até junho de 2021, ilustra o interesse pelo tema, que tem sido debatido em eventos específicos como o BEMIS - Brazilian English Medium Instruction Seminar, com duas edições já realizadas, em 2018 e 2019.

A fim de conhecer de que modo o IMI tem sido abordado nas publicações brasileiras, realizamos esta metassíntese qualitativa ${ }^{2}$, cujos procedimentos serão detalhados na seção apropriada. Nosso objetivo geral é identificar as tendências dos estudos e sugerir uma agenda de pesquisa que trate de questões ligadas à adoção do inglês como uma das línguas empregadas no ensino superior, no contexto da internacionalização.

\section{INGLÊS COMO LÍNGUA MEDIADORA DO ENSINO-APRENDIZAGEM NO ENSINO SUPERIOR}

Embora amplamente definido como a utilização da língua inglesa para ensino de disciplinas acadêmicas em países onde o inglês não seja a primeira língua da maioria da população, segundo Dearden (2015), o IMI ou Ensino por Meio do Inglês (EMI) tem sido impulsionado no ensino superior como estratégia de internacionalização "em casa $^{13}$. Políticas linguísticas em diversos países têm introduzido o ensino por meio dessa língua, em abordagens que favorecem o aprendizado de conteúdo e língua, como no caso do CLIL (Content and Language Integrated Learning), ou priorizado o conteúdo, como no caso de IMI, cuja realização local pode apresentar variações, ora aproximando-se de uma ou de outra abordagem (BAUMVOL; SARMENTO, 2016).

A revisão de literatura feita por Macaro et al. (2017) revelou grande número de estudos sobre crenças e atitudes, não permitindo tirar conclusões sobre a pertinência de se adotar essa prática ou não. Para eles, são necessárias pesquisas que tragam resultados mensuráveis (bard research evidence), apontando, ao final, para perguntas que poderiam fazer parte de uma agenda de pesquisa com essa finalidade. Por outro lado, Galloway (2020), em revisão feita recentemente para a organização British Council, revela que muitos são os desafios enfrentados. Estes frequentemente relacionam-se a questões linguísticas e a quão preparados os professores e estudantes se sentem, ao papel da língua materna nas aulas em inglês, ao grau de apoio institucional, dentre outros. Embora o ensino da língua não seja objetivo do IMI, muitos gestores acreditam que sim. De modo semelhante a Macaro et al. (2017), Galloway (2020) afirma que (p. 56):

[...] preditores de sucesso em IMI também são pouco pesquisados. Isso requer estudos mais aprofundados, a fim de descobrir onde os alunos precisam de mais apoio, como o IMI pode ser melhor implementado para aprimorar os resultados dos alunos e como isso varia de acordo com a disciplina que está sendo cursada. ${ }^{4}$

A autora também aponta para uma agenda de pesquisa que trate de questões como quais são as boas práticas em IMI em estudos comparativos sobre as diferentes abordagens adotadas, os tipos de apoio linguístico necessários

1. Original: The network responds to the scarcity of research examining what is happening at the practical level, the need for materials and for increased collaboration amongst content and language specialists. By exploring how government policy goals are being operationalised at the institutional and classroom level, we aim to improve the quality of provision. Successful EMI policy implementation requires careful planning to avoid unrealistic expectations and disappointment.

2. Definida como "integração interpretativa de achados qualitativos (derivados de estudos fenomenológicos, etnográficos, da teoria fundamentada nos dados e outros) que são a síntese interpretativa de dados" (MATHEUS, 2009, p. 544).

3. "Qualquer atividade relacionada internacionalmente, com exceção de atividades de saída e mobilidade de estudantes e pessoal" (WÄTCHER, 2000, p. 6, tradução nossa).

4. Original: Predictors of success in EMI are also under-researched. This needs further investigation in order to uncover where students require further support, how EMI may be better implemented to enhance student outcomes, and how this differs according to the academic subject being studied. 
para estudantes, bem como níveis de proficiência desejáveis, ao lado de definições de que inglês seria mais adequado em contextos caracterizados por seu uso como língua franca e comunicação bi/multilíngue.

Considerando que também em nosso país tem crescido o interesse por IMI, pareceu-nos relevante realizar este estudo, de modo a subsidiar decisões sobre políticas linguísticas para internacionalização, levando em conta pesquisas já realizadas. Na próxima seção, detalhamos os procedimentos de geração dos dados e as categorizações adotadas.

\section{METODOLOGIA DO ESTUDO}

Segundo Matheus (2009), na metassíntese qualitativa, é possível agrupar estudos, buscando convergências e divergências, porém sem compará-los. Seu objetivo é apresentar sugestões para a melhoria dos resultados, fortalecendo os objetivos de pesquisas com o propósito de fundamentar novas práticas, explorar teorias e discutir aspectos políticos que envolvem esses estudos. As etapas para esse tipo de análise são, de acordo com aquela autora (MATHEUS, 2009, p. 545):

1. Identificar o interesse intelectual e o objetivo da pesquisa;

2. Decidir o que é relevante aos critérios iniciais de inclusão dos estudos;

3. Ler os estudos;

4. Determinar como os estudos estão relacionados;

5. Elaborar novas afirmações sobre o conjunto dos resultados;

6. Elaborar a nova explicação, que seja equivalente a todos os estudos pesquisados.

Neste estudo, definimos inicialmente o período de dez anos (2010-2020) para a consulta às seguintes bases de dados: Banco de Teses da CAPES, Portal de Periódicos da CAPES, Google Scholar e Portal Scielo. Nessas bases, selecionamos apenas os textos produzidos por pesquisadores brasileiros em estudos sobre nosso contexto, em inglês ou em língua portuguesa. Os termos consultados no mês de junho de 2020 foram: inglês como meio de instrução, inglês como língua de instrução, ensino em inglês, ensino por meio do inglês, English medium instruction, todos entre aspas para evitar a recuperação de documentos irrelevantes. Além da consulta a essas fontes, foram incluídos capítulos de livros constantes das referências bibliográficas nos textos encontrados em periódicos e de conhecimento dos autores deste artigo ${ }^{6}$.

Os textos foram divididos entre os participantes do projeto, lidos, e informações essenciais foram extraídas e compartilhadas em planilha com os seguintes elementos:

1. Natureza da publicação;

2. Detalhes da obra;

3. Objetivos e perguntas de pesquisa;

4. Referencial bibliográfico sobre IMI;

5. Metodologia;

6. Resultados e discussão;

7. Conclusões/encaminhamentos

8. Observações.

Apesar de ainda ser um tema incipiente nas pesquisas em Linguística Aplicada no Brasil, atualmente o IMI conta com trabalhos em andamento em diversos programas de pós-graduação stricto sensu, orientados por pesquisadores com publicações na área. Uma lista desses trabalhos também foi compilada a partir do currículo lattes de pesquisadores frequentemente citados (orientações em andamento, no Apêndice A). Não obstante esses cuidados, é importante salientar que nosso levantamento não é exaustivo, ainda que tenhamos tomado o cuidado de ampliar as estratégias de busca.

5. "Uso do inglês na comunicação intercultural entre usuários do inglês de qualquer parte do mundo" (JENKINS; LEUNG, 2017, p. 2, tradução nossa).

6. Na área de Linguística Aplicada, tem sido frequente a publicação em capítulos de livros, que esperamos ter capturado parcialmente na consulta ao Google Scholar. 
Para classificação dos estudos quanto a seus objetivos, adotamos os critérios de Gil (2019), utilizando as categorias exploratória, descritiva e explicativa, à qual acrescentamos o qualificativo especulativo. Se exploratória, os objetivos estariam ligados a compreender melhor quais práticas ou atitudes orientavam o IMI; se descritivas, os objetivos visariam descrever práticas pedagógicas mediadas pelo inglês, se explicativa-especulativa, incluiria textos de natureza argumentativa, não baseados em dados empíricos, mas resultantes de reflexões a partir de referenciais teóricos. Nos casos em que um texto pudesse comportar mais de uma categoria, fizemos essa indicação. Com relação a seus encaminhamentos, seguimos Park e Wee (2012). Para esses autores, políticas linguísticas podem ser direcionadas para acomodação ou reconfiguração das práticas formuladas para moldar comportamentos linguísticos. As políticas direcionadas à acomodação ao mercado caracterizam-se por aceitar a estrutura vigente (no caso, aceitar que o inglês seja a língua dominante da internacionalização, com reflexos inclusive no ensino). Por outro lado, as políticas de reconfiguração buscam colocar em xeque essa estrutura ou problematizá-la, objetivando a transformação do mercado linguístico. A adoção desses parâmetros para análise dos estudos nos permite tecer considerações sobre as tendências das pesquisas sobre IMI no contexto brasileiro e apontar possíveis temas para uma agenda de internacionalização crítica (VAVRUS, PEKOL, 2005).

\section{RESULTADOS E DISCUSSÃO}

Com relação ao número de publicações identificadas no levantamento inicial, o Quadro 1 apresenta os dados quantitativos.

Quadro 1. Total de trabalhos encontrados por categorias.

\begin{tabular}{|l|c|}
\hline \multicolumn{1}{|c|}{ Categorias } & Quantidade de trabalhos encontrados \\
\hline Artigos em periódicos & 11 \\
\hline Capítulos de livro & 6 \\
\hline Trabalhos completos de anais de evento & 2 \\
\hline Relatórios & 3 \\
\hline Dissertações de mestrado & 2 \\
\hline Apresentações (slides) de eventos & 2 \\
\hline Resumos de eventos & 2 \\
\hline Artigos no prelo & 2 \\
\hline Total: 30 trabalhos. & \\
\hline
\end{tabular}

Fonte: os próprios autores.

Nas próximas seções, apresentaremos considerações sobre os textos com base na classificação dos objetivos das pesquisas.

\section{1) Pesquisas exploratórias}

Nas pesquisas exploratórias, encontramos percepções (crenças, atitudes) e motivações sobre IMI, de forma geral (e.g. GIMENEZ et al., 2020; BAUMVOL, 2016; BAUMVOL; SARMENTO, 2019a; 2019b; BÜHRER, 2019; EL KADRI; FINARDI; TAQUINI, 2021; MARENGO; SARMENTO, 2019; RIOS-REGISTRO; MOSS; SCHMITT, 2018) e sobre aspectos como: papel do professor (STALLIVIERI , GONÇALVES, 2015); pronúncia (HAUS, 2018); inteligibilidade (MARTINEZ; PALMA, 2020); preparo linguístico para IMI (RIOS-REGISTRO; MOSS; SCHMITT, 2018). Também há trabalhos que analisam expectativas e impressões de participantes de cursos

7. Com relação ao Google Scholar, foram eliminadas da lista as publicações repetidas e aquelas que não tinham como foco de estudo o IMI, mas apenas o mencionaram, assim como estudos em português, mas sobre outros países como, por exemplo, Moçambique. 
de IMI (MARTINEZ; FERNANDES, 2020; ZÜGE; BARRETO; NOVELLI, 2020) ou relatam experiências desses cursos (RODRIGUES, ROCHA, 2020; VERDU, 2017). Além disso, nesse tipo de pesquisa, o trabalho de Martinez, Fogaça e Figueiredo (2019) é voltado para a compreensão de iniciativas em apoiar ou orientar IMI. No total, 16 trabalhos fazem parte desta classificação.

Para captar percepções, motivações e expectativas, vários foram os instrumentos utilizados: questionários; entrevistas; grupo focal; análise de documentos; observação (participante). Os participantes das pesquisas foram acadêmicos de várias áreas de conhecimento; docentes de diferentes disciplinas que ministram aulas em inglês; docentes que frequentaram cursos de IMI, além de gestores de duas universidades em específico (GIMENEZ et al., 2020). A maioria das pesquisas são de natureza qualitativa, com exceção de El Kadri, Finardi, Taquini (2021), Sarmento e Baumvol (2019a; 2019b) e Marengo e Sarmento (2019), que possuem cunho misto/natureza quanti-qualitativa. A investigação de Sarmento e Baumvol (2019a; 2019b) e Marengo e Sarmento (2019) teve um grande número de participantes: 5.119 professores de todas as unidades federativas do país que responderam a um questionário on-line com perguntas abertas e fechadas. Em algumas propostas, foram desenvolvidos estudos de caso em uma disciplina específica (EL KADRI, FINARDI; TAQUINI, 2021; STALLIVIERI; GONÇALVES, 2015). Muitos dos dados foram analisados por meio de Análise do Conteúdo (BAUMVOL, 2016; HAUS, 2018; VERDU, 2017), e a pesquisa de El Kadri, Finardi e Taquini (2021) utiliza uma perspectiva ecológica tendo como base o conceito de representação da Análise Crítica do Discurso (ACD).

Os resultados apontam, ao mesmo tempo, motivações externas, como a demanda de alguns programas de pós-graduação, e motivações internas, relacionadas à aprendizagem de vocabulário, leitura de textos, aprimoramento linguístico e aprendizagem/prática do inglês, desenvolvimento de pesquisas e participação em eventos de suas áreas de atuação; intercâmbios etc. (BAUMVOL, 2016). Nos resultados apresentados por essa autora, a adoção de IMI também está relacionada à necessidade de inserir os alunos brasileiros no contexto internacional de produção e difusão do conhecimento, ou seja, de qualificá-los para que possam agir e participar de práticas em diferentes contextos acadêmicos e científicos por meio da língua inglesa. Há um destaque da influência de agentes das áreas de Educação e de Linguística Aplicada em contextos de IMI de modo a promover uma internacionalização inclusiva e empoderadora. Os resultados deste estudo dialogam com os de Gimenez et al. (2020), ao também evidenciarem a demanda de agências externas para a adoção do IMI, a inserção de alunos brasileiros em contextos internacionais, o desenvolvimento linguístico de professores e alunos para oportunidades em um mundo globalizado.

Adicionalmente ao enaltecimento do desenvolvimento linguístico ou a aprendizagem/prática da língua inglesa como a motivação principal de alunos e professores para IMI (BAUMVOL, 2016; BAUMVOL; SARMENTO, 2019a; MARENGO; SARMENTO, 2019) reconhece-se também essa prática como uma estratégia para aumentar a internacionalização em casa (VERDU, 2017); além de destaque ao fato de docentes se preocuparem mais com a comunicação do que com a correção gramatical (GIMENEZ et al., 2020). O estudo de El Kadri, Finardi e Taquini (2021) ainda destacou que o IMI é representado como possibilidade de melhoria do inglês e do letramento acadêmico e que a falta de proficiência pode comprometer a participação e o desempenho dos alunos em cursos de IMI. Nessa linha, a pesquisa de Bührer (2019) indicou uma aceitação da prática; no entanto, as preocupações giram em torno da proficiência, domínio, fluência da língua tanto de aluno quanto de professores. Assim, Rios-Registro, Moss e Schmitt (2018) especulam que a melhora na proficiência linguística e treinamento em metodologia de IMI, somados a um incentivo institucional para professores lecionarem em inglês, poderiam resultar em práticas mais fortalecidas de IMI nas universidades que participaram da sua pesquisa.

Alguns estudos trazem viés positivo em relação ao IMI (STALLIVIERI; GONÇALVES, 2015), enquanto outros identificam a falta de compreensões mais críticas sobre ele (GIMENEZ et al., 2020) ou sobre o inglês em geral e em cursos de IMI em particular. Na pesquisa de El Kadri, Finardi e Taquini (2021), por exemplo, as representações do inglês estão ligadas à sua naturalização como língua acadêmica/da internacionalização. O trabalho de Haus (2018), que analisou as crenças sobre pronúncia, identificou a coexistência de dois discursos conflitantes: um com foco na inteligibilidade e outro que enfatiza o "uso correto" da língua. Assim, a pesquisadora ressalta a importância de abordar o Inglês como Língua Franca na formação de professores para IMI. Outro estudo (MARTINEZ; PALMA, 2020), com foco na inteligibilidade, destacou que professores com nível B2 ${ }^{8}$, ou maior, foram considerados pela maioria dos

8. O nível B2, de acordo com o Common European Framework of References for Languages (COUNCIL OF EUROPE, 2020), revela proficiência em nível intermediário. 
alunos como aptos para ensinar em inglês. Embora a maioria dos participantes da pesquisa de Rios-Registro, Moss e Schmitt (2018) tivessem nível B2, os autores concluíram que seria necessário melhorar a proficiência de professores no Paraná; provavelmente em função do baixo poder de generalização do estudo qualitativo realizado.

Há ainda preocupações com questões que envolvem inclusão/exclusão ou desigualdades nessa prática (GIMENEZ et al., 2020; BAUMVOL; SARMENTO, 2019a; 2019b). Comparando percepções em diferentes áreas do conhecimento, os estudos de Baumvol e Sarmento (2019a; 2019b) também identificaram maior aceitação do IMI em áreas ligadas a Ciências Exatas e da Vida, e menor aceitação nas Ciências Humanas, Linguística, Literatura e Artes, resultado também corroborado pela análise de documentos da área da CAPES (GIMENEZ; OLIVEIRA; AMARAL, no prelo). Por outro lado, o trabalho de Baumvol (2016) ressaltou que os agentes das áreas de Educação e de Linguística Aplicada podem (e devem) trazer contribuições importantes para que a prática de IMI promova uma internacionalização inclusiva e empoderadora para todos os envolvidos.

Na pesquisa de Stallivieri e Gonçalves (2015), o papel do professor fica evidenciado pelas respostas dos alunos, que sinalizam para os excelentes resultados da disciplina sobre interculturalidade. Eles apontam domínio inglês pelo professor, seu profundo conhecimento do conteúdo apresentado, a utilização de metodologias inovadoras e a forte interação proporcionada pela presença de estudantes estrangeiros. Esse estudo denota a necessidade de pesquisas aprofundadas sobre o tema com o objetivo de discutir as razões para o ensino de conteúdos em línguas estrangeiras, o perfil dos estudantes, o conteúdo e as atividades a serem desenvolvidas, a metodologia, e, acima de tudo, as competências e habilidades dos professores que ministrarão as aulas (DEARDEN, 2015).

Em relação às expectativas e impressões de participantes de cursos de IMI, os resultados demonstraram a utilidade do curso para "desenvolver habilidades linguísticas, sociais e pedagógicas, não apenas nas aulas ministradas em LI, mas também na prática docente como um todo" (ZÜGE; BARRETO; NOVELLI, 2020, p. 60). O estudo de Martinez e Fernandes (2020) também destacou a motivação dos professores para ministrar suas aulas em LI a partir dos cursos ofertados e a possibilidade de uso das estratégias vistas no curso de IMI para as aulas ministradas em português.

Além disso, por meio de um relato de experiência, Rodrigues e Rocha (2020) apresentam componentes de um curso de formação continuada em IMI para professores da pós-graduação das Universidades Federal e Estadual do Piauí. Além dos relatos sobre o curso, as autoras enfatizam o impacto que essa iniciativa pode ter no processo de internacionalização na instituição. Em suas discussões e resultados, Rodrigues e Rocha (2020) ressaltam o trabalho conjunto entre professores de conteúdo e especialistas em inglês a fim de contribuírem para o desenvolvimento linguístico direcionado à internacionalização das universidades. Embora tenha sido um curso relacionado ao desenvolvimento de aulas em IMI, os objetivos pareceram ser voltados a práticas de Inglês para Fins Acadêmicos (IFA), uma vez que enfatizaram apresentações orais em inglês, escrita de textos, metodologia de pesquisa em inglês, entre outros, sugerindo interligações entre IFA em IMI.

Também na parte de pesquisa exploratória, Martinez, Fogaça e Figueiredo (2019) apresentam o desenvolvimento e a validação de um instrumento de observação de aula elaborado para contextos de IMI. Para os autores, o instrumento se mostrou capaz de medir construtos relacionados ao engajamento do aluno e à confiança do professor, o que pode, posteriormente, elucidar até que ponto a falta de interesse do aluno pode ser atribuída à proficiência em inglês ou à pedagogia.

A partir da apresentação das pesquisas exploratórias, observamos que nove delas tem um caráter de acomodação; ou seja; tem viés positivo ou de aceitação sem questionamentos em relação ao IMI ou aos aspectos investigados (BÜHRER, 2019; MARENGO; SARMENTO, 2019; MARTINEZ; FERNANDES, 2020; MARTINEZ; FOGAÇA; FIGUEIREDO, 2019; MARTINEZ; PALMA, 2020; RIOS-REGISTRO; MOSS; SCHMITT, 2018; STALLIVIERI; GONÇALVES, 2015; VERDU, 2017; ZÜGE; BARRETO; NOVELLI, 2020).

As sete classificadas como de reconfiguração apontam: i) o trabalho conjunto dos professores de línguas (RODRIGUES; ROCHA, 2020) ou de Educação e de Linguística Aplicada com professores de outras áreas do conhecimento como importantes para uma internacionalização inclusiva e empoderadora (BAUMVOL, 2016); ii) o uso mais crítico e informado do inglês (EL KADRI; FINARDI, TAQUINI, 2021); iii) a perspectiva do Inglês como Língua Franca (HAUS, 2018) para refletir sobre ideologias linguísticas ou sobre outros aspectos relacionados à linguagem (GIMENEZ et al., 2020); iv) uma prática inclusiva de IMI, principalmente para alunos de baixa renda, e um incentivo a aulas de inglês por meio de programas como o Idiomas sem Fronteiras; Paraná Fala Inglês, dentre outros (SARMENTO; BAUMVOL, 2019a, 2019b). 


\section{2) Pesquisas descritivas}

As pesquisas que caracterizamos como descritivas são aquelas cujos objetivos visam descrever práticas mediadas pelo inglês de modo a caracterizar iniciativas locais. Nessa categoria, nove trabalhos se encaixaram nesse tipo de classificação. Dentre esses, temos pesquisas com foco em implementações locais - algumas com foco em práticas pedagógicas locais, mais especificamente, cursos (JORDÃO, 2016; MACIEL; VERGARA, 2019) e outras com foco na análise local de políticas institucionais. Neste grupo, estão as pesquisas de Bleggi (2019), Taquini (2020) e Gimenez et al. (2020). As pesquisas com focos mais abrangentes objetivam mapear a implementação do IMI de maneira mais genérica no país como um todo (GIMENEZ; OLIVEIRA; AMARAL, no prelo; GIMENEZ et al., 2018; BAUMVOL; SARMENTO, 2019; MARTINEZ, 2016).

Em relação aos objetivos dos trabalhos que focam na descrição de implementações locais, mais especificamente, Maciel e Vergara (2019) exploram o aspecto de internacionalização como prática local ou internacionalização em casa. Os autores apontam para estratégias voltadas para fortalecer o papel da língua na internacionalização do ensino superior por meio da descrição da proposta de English Club como um espaço para atividades de desenvolvimento linguístico planejado e executado como uma atividade de extensão por acadêmicos do curso de medicina de uma universidade pública. Jordão (2016) relata um curso realizado em sua instituição e examina uma dimensão dessa prática institucional estabelecida para dar conta de forjar identidades e sentimentos construídos por uma perspectiva discursiva decolonial ${ }^{9}$.

Os trabalhos que visam mapear diversas implementações, o fazem com objetivos similares, porém com amplitude e foco diferenciados. Baumvol e Sarmento (2016) objetivam discutir o papel das línguas adicionais no processo de internacionalização das universidades e abordar o fenômeno da instrução com base no conteúdo e o IMI em suas possíveis gradações, bem como as diferentes terminologias adotadas pela literatura internacional da área para referir-se a modelos relativamente semelhantes de instrução com base no conteúdo. Baumvol e Sarmento (2019) apresentam as boas práticas de IMI com base na literatura e enfatizam as diferentes configurações para as práticas de IMI. Martinez (2016) traz uma descrição de oferta de IMI em diferentes contextos e um retrato do cenário atual de IMI no Brasil e Gimenez et al. (2018) objetivam mapear e atualizar informações sobre o IMI no Brasil no período 2017-2019. Gimenez, Oliveira e Amaral (no prelo) analisam os documentos oficiais de áreas do conhecimento na pós-graduação no quesito "Perspectivas do processo de internacionalização dos PPGs" para identificar questões relacionadas ao inglês como meio de instrução.

Em relação à metodologia, os trabalhos também podem ser categorizados pela descrição de implementações locais ou de mapeamentos mais genéricos sobre o estado da arte da pesquisa/implementação. No primeiro grupo, a metodologia coincide com aquela adotada para o design do curso implementado. Maciel e Vergara (2019), por exemplo, relatam procedimentos metodológicos na disciplina de Iniciação aos Fundamentos Científicos (IFC). Os autores apontam que a proposta se pautou em uma perspectiva de metodologia ativa, seguindo a orientação do Problem-Based Learning (PBL), de um processo de design e redesign e na proposta de sala de aula invertida. Jordão (2016), por seu turno, baseou o curso em uma perspectiva decolonial com a análise realizada por meio da literatura da perspectiva pós-estruturalista para interpretar a experiência.

Os estudos que tratam de mapeamentos mais genéricos sobre o estado da arte da pesquisa/implementação tendem a não explicitar a metodologia adotada, mas podemos ressaltar que tiveram como foco: o mapeamento dos tipos de IMI existentes na literatura (BAUMVOL; SARMENTO, 2019); a análise de documentos, entre esses a análise dos documentos oficiais das Nações Unidas e do Plano Nacional de Educação (BAUMVOL; SARMENTO, 2016) e documentos de área no site da CAPES (GIMENEZ; OLIVEIRA; AMARAL, no prelo) e uma revisão bibliográfica (MARTINEZ, 2016).

Os resultados dos trabalhos descritivos de cursos/iniciativas locais apontam que cursos preparatórios para docentes podem representar uma possibilidade de professores buscarem outras perspectivas metodológicas e outras experiências de aprendizagem além das tradicionalmente adotadas no ensino de línguas (MACIEL; VERGARA, 2019). Os resultados nessa categoria indicam, ainda, que a resistência em relação ao ensino de línguas estava

9. Segundo Oliveira $(2016$, p.1), refere-se $[\ldots .$.$] "às possibilidades de um pensamento crítico a partir dos subalternizados pela modernidade$ capitalista e, na esteira dessa perspectiva, a tentativa de construção de um projeto teórico voltado para o repensamento crítico e transdisciplinar, caracterizando-se também como força política para se contrapor às tendências acadêmicas dominantes de perspectiva eurocêntrica de construção do conhecimento histórico e social". 
fortemente entrelaçada ao modo como professores concebiam a língua, e mais especificamente o inglês, nas suas vidas pessoais e profissionais. Isto revela que as experiências passadas como usuários são determinantes para as percepções de proficiência e a falta de confiança associada ao inglês (JORDÃO, 2016).

Em relação aos resultados das pesquisas mais genéricas, Baumvol e Sarmento (2019) apontam que o IMI a) não é apenas para atrair alunos estrangeiros. Acrescentam que no contexto atual das instituições de ensino superior brasileiras aulas com IMI envolvem, sobretudo, alunos e professores brasileiros, b) possui alcance mais amplo, se comparado com a mobilidade, c) tem o objetivo de proporcionar situações de prática e contato com o inglês, práticas acadêmicas e aprendizado e uso da terminologia da área por alunos e professores brasileiros em casa, d) fomenta novas metodologias em sala de aula de educação superior e e) possibilita a promoção do desenvolvimento linguístico e profissional de professores e alunos brasileiros, que estarão preparados para aproveitar diversas oportunidades neste mundo globalizado e disseminar o conhecimento produzido no país.

O levantamento de Gimenez et al. (2018) aponta um aumento das disciplinas em IMI desde 2016, preponderância dos cursos de pós-graduação e uma grande incidência de disciplinas extracurriculares oferecidas pelas instituições brasileiras. Por outro lado, Martinez (2016) ressalta que o IMI no Brasil está ainda na infância, mas crescendo rápido; que ele traz oportunidades para aprender com as experiências dos outros ao redor do mundo, tem tido efeito positivo na motivação dos alunos, tem contribuído com a 'internacionalização em casa' e promovido melhoria da prática reflexiva e da prática de sala de aula de professores do ensino superior e a colaboração entre professores de outras áreas que lecionam em inglês e especialistas da área da linguagem. Aponta, no entanto, a pouca comunicação entre pessoas (e.g. departamentos, corpo docente) que ensinam em inglês e a sugestão de que o IMI no Brasil não deveria seguir nenhum modelo, mas sim construir o nosso próprio. Gimenez, Oliveira e Amaral (no prelo) revelam que diferentes áreas do conhecimento listam IMI de modo explícito ou implícito em suas diretrizes para a pósgraduação, e planejamentos estratégicos institucionais poderão direcionar esforços para atendimento desse requisito, considerando a importância do financiamento a partir do processo de avaliação por pares.

Baumvol e Sarmento (2016) indicam que a prática do IMI tem sido adotada, geralmente, através de iniciativas isoladas de professores, em suas áreas específicas, não relacionadas ao ensino e aprendizagem de línguas. Ressaltam também que é comum que esses professores tenham extensa experiência em seus campos de atuação e poucas oportunidades de formação pedagógica e de reflexão sobre questões ligadas à prática docente, como a relação entre conteúdo e língua.

Algumas das pesquisas descritivas concentram-se também na análise local de políticas institucionais. Neste grupo, estão as pesquisas de Bleggi (2019), Taquini (2020) e Gimenez et al. (2020). Bleggi (2019) analisa como uma universidade pode proporcionar aos discentes de pós-graduação o nível de inglês para o mercado de trabalho global atual. Taquini (2020) objetiva refletir sobre o papel das línguas estrangeiras/adicionais (L2) no processo de internacionalização do ensino superior analisando o papel das L2 em geral e do inglês em particular no processo de internacionalização da UFES, enquanto Gimenez et al. (2020) analisam a situação do IMI em duas universidades estaduais do Paraná, focalizando as políticas, atitudes, práticas e as ideologias linguísticas que informam as práticas de IMI, além dos desafios encontrados e o papel do inglês e do português neste processo.

Os estudos descritivos geralmente caracterizam-se por estudos de caso (BLEGGI, 2019; GIMENEZ et al., 2020; TAQUINI, 2020), pois tratam de contextos locais específicos. Bleggi (2019), tendo como objeto os Programas de Pós-Graduação da UFPel com conceitos 6 e 7 da CAPES, realizou entrevistas semi-estruturadas com os coordenadores dos programas selecionados, seguidas de análise interpretativa para verificar se a língua inglesa é importante nesse nível de formação e que ações a UFPel poderia realizar para melhorar a habilidade de comunicação na língua pelos discentes. Além disso, buscou verificar se os coordenadores conhecem o IMI e se existem disciplinas ministradas em inglês nos Programas.

Taquini (2020) triangulou dados quantitativos e qualitativos da oferta de L2 da UFES no Guia IMI 2018-2019 (GIMENEZ et al., 2018) com dados da proficiência em L2 autodeclarada no currículo lattes de 1.156 professores de PPGs dessa universidade, e Gimenez et al. (2020) utilizaram entrevistas semi-estruturadas, grupo focal e questionário com membros da comunidade acadêmica em ambas as instituições (Universidade Estadual de Londrina e Universidade Estadual de Maringá), incluindo administradores, professores da pós-graduação e alunos.

Os resultados dessas pesquisas permitem às instituições terem conhecimento local sobre o IMI, seja com relação ao número de disciplinas ministradas em inglês, as percepções dos envolvidos e o grau de implementação (GIMENEZ et al., 2020; BLEGGI, 2019; TAQUINI, 2020). Mais especificamente, Bleggi (2019), por exemplo, 
constata que, enquanto já existem disciplinas ministradas em inglês em alguns PPG, outros não pretendem implementar ações desse tipo. No entanto, há, de alguma forma, atividades que exigem o conhecimento de inglês, parecendo ser consenso a importância do conhecimento da língua na formação acadêmica em nível de pós-graduação.

Taquini (2020) também aponta que o inglês aparece como principal L2 para a internacionalização, o que, segundo ela, confirma a visão colonial e hegemônica do Norte Global e que, se for imposto de forma acrítica, pode fortalecer e perpetuar a colonialidade (CASTRO-GOMÉZ, 2007). A autora também indica que, assim como no Guia IMI (GIMENEZ et al., 2018), os dados da UFES se colocam como um microcosmo de uma realidade nacional (e regional, no caso do Sul Global) que corrobora o inglês como a língua primordial da internacionalização, processo que vem sendo modelado pelo Norte Global, imitando modelos, práticas e línguas hegemônicas.

O trabalho de Gimenez et al. (2020) assinala que ambas as universidades pesquisadas possuem políticas linguísticas específicas que dão suporte às práticas institucionais, mas uma delas possui uma tradição mais forte ligada à implementação do IMI. Conforme já mencionado na seção anterior, a pesquisa também demonstrou que os participantes estão mais interessados nos elementos comunicativos do IMI do que em aspectos gramaticais da língua e que a conscientização da perspectiva do inglês como língua franca tem potencial de contribuir para a superação dos obstáculos no uso do IMI, quando o foco é na comunicação e não nos aspectos linguísticos. Gimenez et al. (2020) também enfatizam que embora os participantes avaliem o IMI positivamente, há a preocupação de muitos professores com o acirramento das desigualdades.

Em relação aos encaminhamentos dos estudos descritivos, estes se dividem na categoria de acomodação (3 estudos) e reconfiguração (7 estudos). O primeiro que se encaixa em estudo de acomodação, talvez por sua própria natureza de levantamento, é o relatório de Gimenez et al. (2018), que visa mapear cursos e atividades em inglês no Brasil. O segundo é o trabalho de Bleggi (2019), que fornece encaminhamentos para IMI na instituição, como por exemplo ações de conscientização acerca da importância da língua inglesa, capacitação de docentes, incorporação das atividades do IsF e cadastro de atividades acadêmicas realizadas em inglês, entre outros. Baumvol e Sarmento (2019) concluem que o IMI tem potencial de maximizar o aprendizado do inglês acadêmico de professores e alunos, encorajar a educação internacional e permitir que estudantes estrangeiros se interessem pela língua portuguesa, além de possibilitar que a produção escrita em inglês seja disseminada globalmente.

Na perspectiva de reconfiguração, encontramos os estudos de Maciel e Vergara (2019), Martinez (2016), Jordão (2016), Baumvol e Sarmento (2016), Gimenez et al. (2020), Taquini (2020) e Gimenez, Oliveira e Amaral (no prelo), que, embora sejam de natureza descritiva, tecem reflexões que questionam ou problematizam, de algum modo, o status quo do IMI no Brasil.

Maciel e Vergara (2020) sugerem expandir a concepção do IMI a partir de uma perspectiva multimodal. Martinez (2016) acredita que o Brasil pode aprender com outros, mas ao mesmo tempo, trilhar seu próprio caminho e encontrar uma posição única de adoção do IMI que nos permita nos beneficiar do que os outros têm feito enquanto inovam em sua pesquisa e implementação. Jordão (2016) expressa claramente sua preocupação com os efeitos do uso do IMI e suas implicações políticas no Brasil, sugerindo a problematização, a necessidade de revisão de conceito de língua e da posição do inglês.

Baumvol e Sarmento (2016) apontam a pouca investigação que tenha a sala de aula como foco e avançam os estudos sugerindo ser fundamental a inclusão não apenas da perspectiva dos linguistas aplicados, mas também dos envolvidos em cada disciplina acadêmica, os quais propõem, planejam e implementam aulas em inglês. Sugerem, ainda, que a adoção de práticas de IMI por IES brasileiras podem (e devem) servir para empoderar alunos brasileiros de forma a aumentar sua participação em diferentes situações acadêmicas que envolvam o uso do inglês, em diferentes níveis de gradação.

Gimenez et al. (2020) defendem a inclusão da perspectiva do Inglês como Língua franca nas propostas de IMI porque consideram-na importante para a discussão linguística no debate das práticas de internacionalização, pelo seu potencial de contribuir com a reflexão da comunidade acadêmica sobre as ideologias linguísticas e com a compreensão de outros aspectos relacionados à língua inglesa.

Taquini (2020) problematiza o fato de o inglês aparecer como principal L2 para a internacionalização, confirmando a visão colonial e hegemônica do Norte global, mas com potencial de oferecer possibilidade de diálogos Sul-Sul entre os países do Sul global, como forma de resistir a práticas coloniais (CASTRO-GOMÉZ, 2007). A autora sugere uma visão decolonial em relação à internacionalização e ao papel das L2 nesse processo. 
Gimenez, Oliveira e Amaral (no prelo) apontam que o IMI está em crescimento ao redor do mundo e no Brasil, mas sem muita contestação, e para a necessidade de complementar a análise realizada dos documentos por investigações mais detalhadas e de cunho qualitativo, junto a docentes, buscando verificar de que modo os implícitos da avaliação são percebidos e quanto estes direcionam suas práticas docentes em contextos de grande competitividade por recursos.

\section{3) Estudos explicativos-especulativos}

Os textos categorizados como explicativos-especulativos, conforme mencionado na seção de metodologia, incluem os de natureza argumentativa, não baseados em dados empíricos, mas resultantes de reflexões a partir de referenciais teóricos. Nesta definição, encontramos apenas 5 textos: Gimenez (2019), Jordão et al. (2020), Jordão (2019), Moore e Finardi (2020) e Guimarães e Kremer (2020). Geralmente problematizam a adoção do IMI, buscando promover reflexões críticas sobre seus efeitos no Brasil. Demonstram preocupação com ações relacionadas ao IMI (tanto nas pesquisas quanto nas implementações práticas) e convidam a fazer reflexões localmente informadas.

Gimenez (2019) sugere cautela na introdução do IMI, considerando o pouco volume de pesquisas nessa área em nosso contexto, apontando que justificativas iniciais parecem carecer de reflexões mais aprofundadas sobre os efeitos dessa prática e se baseiam na tendência ditada por universidades de países do Norte Global. Jordão et al. (2020) problematizam as posições da língua inglesa no processo de internacionalização, situando o lócus de enunciação em perspectivas decoloniais, do Sul Global. Questionam o status do IMI, que tem sido visto como uma "febre" - na qual ministrar aulas em inglês parece ser o elemento central que define o grau de internacionalização de uma universidade. Moore e Finardi (2020) discutem o papel do inglês na internacionalização no Sul geopolítico (da Espanha) e do Norte (Europa) e destacam uma parceria geopolítica geográfica do Norte (Espanha) e Sul (Brasil). Guimarães e Kremer (2020) discutem a adoção do IMI nos contextos brasileiro e belga, considerando a influência da globalização e da internacionalização do ensino superior. Por outro lado, Jordão (2016), explora alternativas do tratamento convencional dado ao IMI e reflete sobre um curso que tinha como foco abordar as construções identitárias no inglês por parte dos professores, em perspectiva decolonial.

Essas produções geralmente são do tipo ensaio. Gimenez (2019), Guimarães e Kremer (2020) e Moore e Finardi (2020) realizam revisão de literatura, com identificação de áreas para pesquisa. Jordão et al. (2020) e Jordão (2016) também se enquadram no tipo ensaio argumentativo, o primeiro, trazendo suporte de dados de percepção de discentes e docentes e o segundo com considerações da própria autora.

Alguns textos problematizam a perspectiva de IMI por meio de questionamentos e reflexões necessárias ao contexto brasileiro. Nessa categoria, Gimenez (2019) aponta para a necessidade de desafiar o discurso de que o IMI é sinônimo de internacionalização, sem, no entanto, negar a importância do inglês como língua da comunicação acadêmica internacional e seu papel na mobilidade, cooperação internacional e visibilidade das pesquisas. Para a pesquisadora, é necessário estabelecermos relações mais simétricas ao promovermos o português como língua acadêmica e desvelarmos as ideologias que mantêm o IMI como fator excludente de outras possibilidades. Segundo ela, o IMI tem contribuído para reforçar a ideologia do inglês padrão, com pouca visibilidade ao fato de que seus usuários são falantes não-nativos, com diferentes graus de proficiência. Sugere que decisões sobre IMI levem em conta se isso se apresenta como solução ou como problema, e o papel das ideologias linguísticas reforçadas/desafiadas nessas decisões.

Semelhantes questões são discutidas por Jordão et al. (2020) que sugerem cautela com as propostas de IMI. Para esses autores, as concepções sobre IMI apontam para crenças de que existir no mundo científico está relacionado à língua inglesa, e que sua primazia é vista como imutável nesse cenário. Para eles, essas concepções ressaltam o IMI como um trem em disparada (unstoppable train, cf. MACARO, 2015). Contudo, ainda que reconhecendo a hegemonia do inglês, os participantes de sua pesquisa não se mostraram alheios aos efeitos discriminatórios e excludentes que a promoção inquestionável do inglês como língua de maior alcance na internacionalização pode causar.

Guimarães e Kremer (2020) apontam para duas principais vertentes das pesquisas no Brasil - uma que privilegia o inglês como a língua de comunicação no mundo acadêmico, científico e tecnológico, e outra que critica essa hegemonia em favor de uma abordagem multilíngue. Para contrapor-se a uma visão colonial do inglês, Jordão (2016) propõe uma prática baseada na perspectiva de inglês como língua franca. Esta possibilitaria problematizar atitudes subservientes, questionar a posição do inglês na educação superior e na produção científica e, ainda, desafiar 
os parâmetros de proficiência com base no falante nativo. A autora acredita que as iniciativas locais têm potencial para desafiar práticas de internacionalização tradicionais e que, por isso, é preciso criar espaços de resistência para construir práticas mais igualitárias, ou seja, espaços onde seja possível agir transculturalmente e decolonizar as estruturas de poder, conhecimento e identidades.

Sobre os encaminhamentos, todos os textos explicativos-especulativos se filiam a propostas de reconfiguração, pois problematizam a adoção do IMI entendido como uma prática monolíngue e centrada no falante nativo. Para Jordão et al. (2020), o que deve nos unir nos processos de internacionalização é o interesse no estabelecimento de relações com a diferença, não para perpetuar desigualdades ou reiterar hierarquias, mas para ampliar nossos repertórios de possibilidades. Fazer isso em apenas uma língua, é reduzir a um único universo o multiverso do conhecimento.

Guimarães e Kremer (2020) propõem reflexão sobre a internacionalização de modo a torná-la mais igualitária e sustentável para todas as pessoas do planeta e, assim, evitar modelos opressivos. Moore e Finardi (2020) reforçam o potencial empoderador que o inglês pode ter no processo de internacionalização do ensino superior.

No gráfico 1, apresentamos a categorização dos estudos analisados:

Gráfico 1. Categorização dos estudos analisados (2010-2020).

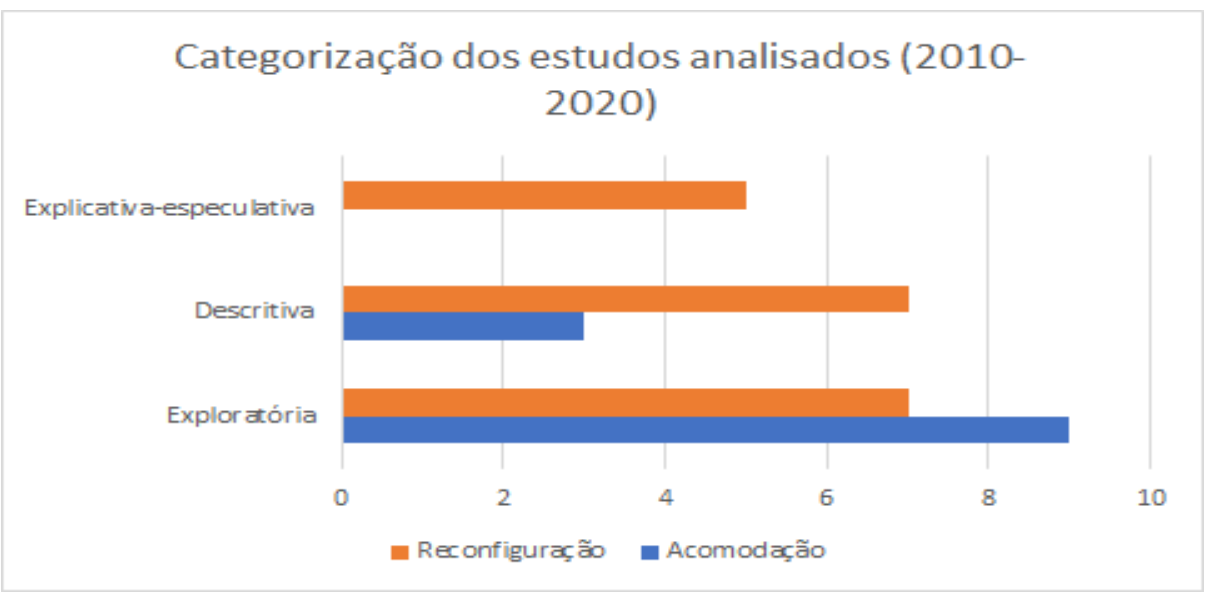

Fonte: os próprios autores.

As pesquisas de caráter mais exploratório tendem a adotar uma perspectiva de acomodação, enquanto que as explicativas-especulativas, por se apoiarem em concepções teóricas de natureza crítica, tendem a propor políticas de reconfiguração.

\section{DISCUSSÃO DOS RESULTADOS}

Os estudos sobre IMI no Brasil, de natureza majoritariamente qualitativa, indicam aproximação ao tema a partir de percepções especialmente de docentes e tem natureza essencialmente descritiva e exploratória. Em sua resenha de Macaro (2018), Knagg (2020) observa que também naquele livro o autor lamentava a maioria dos estudos de pequena escala serem realizados por pesquisadores diretamente envolvidos na implementação dos programas. Ressalva que, longe de culpar os pesquisadores, atribui essa predominância à falta de recursos para pesquisas que pudessem informar boas práticas. Macaro (2018) propõe estudos longitudinais, pesquisa comparada em nível nacional e internacional e foco em resultados de aprendizagem linguístico-educacionais, mais do que apenas concentrar-se em percepções dos envolvidos.

Em nosso contexto, de modo geral, são pesquisadores no campo da Linguística Aplicada, com interesse por políticas linguísticas, que têm se dedicado ao tema, sem necessariamente contar com linhas de pesquisa específicas e recursos suficientes para investigações de maior fôlego. Esses estudos têm se orientado por uma postura diagnóstica, levantando questões que possam ser tratadas em pesquisas mais aprofundadas, como as que vêm sendo realizadas em programas de pós-graduação. De todo modo, emergem muito mais por iniciativas individuais de pesquisadores do que de tomadores de decisões em nível institucional e, naturalmente, se atrelam a linhas de pesquisa com referenciais teórico-metodológicos alinhados com os grupos de pesquisa aos quais se vinculam. Dialogam com a literatura internacional, especialmente a produzida por autores situados no contexto britânico, também ligados à área 
de linguagem. Não surpreende, portanto, que as percepções sejam buscadas em termos da concepção de linguagem endossadas pelos grupos, buscando, inclusive, detectar posturas críticas dentre os investigados.

Além da preocupação com o levantamento das condições sob as quais o IMI vem se realizando e o que pensam os que o realizam, autores brasileiros têm buscado provocar reflexões sobre os impactos da adoção inquestionada do inglês como língua de ensino na pós-graduação, sugerindo algumas estratégias para responder ao que parece ser uma tendência inevitável no processo de internacionalização do ensino superior, algumas delas buscando atender a "demanda" percebida, procurando fazer o melhor possível, e outras levando questionamentos sobre sua pertinência. Essas últimas, por sugerirem uma postura mais cautelosa por parte dos tomadores de decisão, provavelmente terão pouco impacto sobre decisões políticas em maior escala, ainda que possam ser implementadas em casos pontuais, como é o caso de se adotar uma visão de inglês como língua franca (ILF), i.e., admitir que não será apenas o inglês a língua de mediação de aprendizagem, embora esta possa ser a predominante em sala de aula. Essa proposta coadunase com a postura intelectual de pesquisadores filiados a perspectivas decoloniais que veem em algumas vertentes teóricas de ILF a possibilidade de conciliar IMI e ILF, sem se render totalmente às "forças de mercado", buscando reconfigurá-lo (PARK, WEE, 2012). Não surpreendentemente, esses textos são em menor número e em pequena escala, com foco mais em percepções do que em resultados de aprendizagem, que seriam de interesse de tomadores de decisão de políticas linguísticas. Outros encaminhamentos, igualmente alinhados à reconfiguração do "mercado linguístico", buscam fazer propostas de ensino por meio de outras línguas estrangeiras que não apenas o inglês, posicionando-se a partir de leituras decoloniais.

A duplicidade de papéis de pesquisadores brasileiros como educadores de professores para IMI e professores de inglês vinculados a esforços para internacionalização do ensino superior nos coloca desafios ampliados pela ausência de estratégias institucionais de apoio não só a iniciativas para implementação de IMI como também de pesquisas sobre esse contexto. Assim como Macaro (2018), identificamos que a introdução de IMI parece se dar muito mais por docentes/pesquisadores do que por apoio estratégico das instituições. Isso explica por que muitos dos estudos são descritivos e exploratórios visando "acomodação ao mercado". Se docentes/pesquisadores se veem incumbidos de contribuir para a formação dos docentes para IMI, é natural que busquem, dentro de uma postura pedagógica democrática, fazer mapeamentos de percepções e adotem tom cauteloso.

Assim, nos parece que uma agenda de pesquisa sobre IMI, que parta de profissionais de linguagem que estejam envolvidos nos processos formativos de docentes deveria ter caráter etnográfico e foco em questões como:

a) problemas enfrentados por alunos e professores em atividades acadêmicas conduzidas em inglês (BAUMVOL; SARMENTO, 2019);

b) análises de interações nos cursos/disciplinas e dos materiais utilizados para fomentar a discussão das particularidades do IMI no contexto brasileiro;

c) efeitos do IMI sobre as identidades dos sujeitos envolvidos na sua realização;

d) capacidades, percepções e expectativas de docentes que frequentam cursos em IMI, fazendo conexões com processos mais abrangentes de homogeneização de práticas no ensino superior;

e) incorporação de perspectivas empoderadoras que questionem práticas, atitudes e concepções como, por exemplo, a de inglês como língua franca e/ou perspectivas decoloniais;

f) ampliação do referencial teórico para embasar cursos preparatórios de docentes, como, por exemplo, a incorporação de discussões sobre língua, linguagem e ideologias;

g) resultados de aprendizagem linguísticos e de conhecimentos na área alcançados.

Seriam, naturalmente, pesquisas de cunho qualitativo que permitiriam olhar mais detalhadamente como as práticas acontecem e como poderiam acontecer dentro da perspectiva de reconfiguração do inglês no mercado linguístico da internacionalização. Esses estudos seriam complementados por outros que buscassem:

h) entender o impacto das disciplinas ministradas em LI na política de internacionalização das IES (número de alunos que publicam em língua inglesa, realizam mobilidade etc.);

i) razões para não adoção de IMI (e.g. compreensão da visão dos profissionais que não aderiram ao IMI);

j) entender como se dá a ecologia das línguas operando em processos de ensino-aprendizagem, pesquisa e extensão no ensino superior, ou seja, de que modo o IMI se integra a outras práticas no contexto da internacionalização; 
k) identificação das relações entre pesquisas e políticas linguísticas, para (re)configuração de textos e práticas (locais);

1) desvelamento de ideologias que mantêm o IMI como fator excludente de outras possibilidades e que ressaltam que o existir no mundo científico está relacionado à língua inglesa;

m) o impacto que os cursos ministrados em língua inglesa têm tido na política de internacionalização das universidades.

\section{CONSIDERAÇÕES FINAIS}

Objetivamos identificar as tendências dos estudos sobre o IMI e sugerir uma agenda de pesquisa sobre questões ligadas à adoção do inglês como uma das línguas empregadas no ensino superior, no contexto da internacionalização. As pesquisas exploratórias se sobressaem em relação às outras perspectivas e há menor número de estudos voltados para acomodação, sinalizando que a comunidade acadêmica tem questionado e problematizado o IMI no contexto brasileiro, utilizando diferentes vertentes para tal, como a do inglês como língua franca; a decolonialidade; a perspectiva multimodal; a internacionalização crítica, dentre outras.

Esperamos que a agenda de pesquisa elaborada, a partir da revisão dos estudos, possa fomentar outras investigações sobre IMI no Brasil de modo a construir um entendimento local e crítico a respeito dessa prática para o desenvolvimento e o fortalecimento de políticas linguísticas mais abrangentes e inclusivas no cenário de internacionalização acadêmica.

\section{REFERÊNCIAS}

BAUMVOL, L. K. (2016). O uso do inglês como meio de instrução no contexto do ensino superior brasileiro: percepções de docentes. In: IX COLÓQUIO DE LINGUÍSTICA, LITERATURA E ESCRITA CRIATIVA, [DES]LIMIARES DA LINGUAGEM, Porto Alegre, RS. Anais [...]. Pontifícia Universidade Católica do Rio Grande do Sul (PUCRS). p. 362370.

BAUMVOL, L. K.; SARMENTO, S. (2016). A internacionalização em casa e o uso de inglês como meio de instrução. In: BECK, M. S.; MORITZ, M. E.; MARTINS, M. L. M.; HEBERLE, V. (Org.). Echoes: Further Reflections on Language and Literature. 1ed. Florianópolis: UFSC, v. 1, p. 65-82.

BAUMVOL, L. K.; SARMENTO, S. (2019a). Can the use of English as a Medium of Instruction promote a more inclusive and equitable higher education in Brazil? Simon Fraser University Educational Review, v. 12, n. 2, p. 87-105.

BOWLES, H., MURPHY, A. (eds). (2020). English-Medium Instruction and the Internationalization of Universities. London: Palgrave Macmillan.

BLEGGI, A. (2019). O papel da universidade na capacitação dos discentes na proficiência em Língua Inglesa para a Internacionalização. Dissertação de Mestrado em Administração Pública. Universidade Federal de Pelotas, UFPEL, Pelotas.

BÜHRER, É. A. C. (2019). Internacionalização no ensino superior e EMI: um processo "change-tailored". In: JILAC - Jornada Internacional de Linguística Aplicada Crítica, 2019, Brasília. Anais [...] UnB Brasília. p. 296-308.

CASTRO-GÓMEZ, S. (2007). Decolonizar la universidad. La hibris del punto cero y el diálogo de saberes. In: CASTROGÓMEZ, S.; GROSFOGUEL, R. El giro decolonial: reflexiones para una diversidad epistémica más allá del capitalismo global. Bogotá: Siglo del Hombre Editores; Universidad Central, Instituto de Estudios Sociales Contemporáneos y Pontificia Universidad Javeriana, Instituto Pensar, p. 79-93.

COUNCIL OF EUROPE (2020) Common European Framework of Reference for Languages: learning, teaching, assessment Companion Volume with new descriptors. Strasbourg: Council of Europe Publishing. Disponível em: https://www.coe. int/en/web/common-european-framework-reference-languages. Acesso em: 11 maio 2021.

DEARDEN, J. (2015). English as a medium of instruction: A growing global phenomenon. London: British Council. Disponível em: https://www.britishcouncil.es/sites/default/files/british_council_english_as_a_medium_of_instruction.pdf Acesso em: 08 set. 2019. 
DOIZ, A.; LASAGABASTER, D.; SIERRA, J. M. (2013). English-Medium Instruction at Universities: Global Challenges. Bristol: Multilingual Matters.

EL KADRI, M. S.; FINARDI, K. R.; TAQUINI, R. (2021). O inglês como meio de instrução nas representações de alunos de um programa de pós-graduação em ciências biológicas. Horizontes, v. 39, n. 1. Disponível em: https://revistahorizontes.usf. edu.br/horizontes/article/view/1097 Acesso em: 31 maio 2021.

GALLOWAY, N. (2020). English in bigher education. English medium Part 1. London: British Council.

GALLOWAY, N.; KRIUKOW, J.; NUMAJIRI, T. (2017). Internationalisation, higher education and the growing demand for English: an investigation into the English medium of instruction (EMI) movement in China and Japan. ELT Research Papers. London: British Council.

GIL, A. C. (2019). Métodos e técnicas de pesquisa social. 7a. ed. São Paulo, Atlas.

GIMENEZ, T. (2019). Language ideologies and English as a medium of instruction: language policy enactment in Brazilian universities. In: FINARDI, K. R. English in the South (org.). Londrina: EDUEL, p. 51-74.

GIMENEZ, T.; OLIVEIRA, H.; AMARAL, L. (no prelo). Inglês como meio de instrução na pós-graduação stricto sensu no Brasil: uma análise dos documentos de áreas de conhecimento.

GimenEZ, T.; COGO, A.; EL KADRI, M. S.; CALVO, L. C. S. (2020). English as a Medium of Instruction in two statefunded Brazilian higher education institutions from an English as a lingua franca perspective: policy in practice. Relatório "Framing English language applied research British Council". São Paulo, British Council.

GIMENEZ, T.; SARMENTO, S.; ARCHANJO, R.; ZICMAN, R.; FINARDI, K. (2018). Guide to English as a Medium of Instruction in Brazilian Higher Education institutions 2018-2019. São Paulo: British Council. Disponível em: http://faubai.org.br/ britishcouncilfaubaiguide2018.pdf. Acesso em: 31 maio 2021.

GUIMARÃES, F. F.; KREMER, M. M. (2020). Adopting English as a Medium of Instruction (EMI) in Brazil and Flanders (Belgium): A comparative study. Ilha do Desterro. v. 73, n. 1, p. 217-246.

HAUS, C. (2018). Crenças de professores brasileiros de EMI sobre Pronúncia. Revista X, v. 13, n. 2, p. $123-143$.

JORDÃO, C. M. (2019). Intelligibility, mimicry and internationalization. In: Murata, Kumiko (ed). EMI from an ELF perspective. Abingdon: Routledge. p. 32-45.

JORDÃO, C. M. et al. (2020). Internacionalização em inglês: sobre esse tal de unstoppable train e de como abordar a sua locomotiva. Revista Nemit $\square$ rã. v. 1, n. 2.

JORDÃO, C. (2016). Decolonizing identities: English for internationalization in a Brazilian university. Interfaces Brasil/Canadá. Canoas, v. 16, n. 1, p. 191-209.

KNAGG, J. (2020). English Medium Instruction. ELT Journal. v. 74, n. 3, p. 362-365. Disponível em: https://doi.org/10.1093/ elt/ccaa028. Acesso em: 11 mar. 2021.

MACARO, E. (2015). English Medium Instruction: Time to start asking some difficult questions. Modern English Teacher, v. 24, n. 2. p. 4-8. Disponível em: https://www.modernenglishteacher.com/media/5377/macaro.pdf. Acesso em: 29 maio 2021.

MACARO, E. (2018). English medium instruction - content and language in policy in practice. Oxford University Press.

MACARO, E.; CURLE, S.; PUN, J; AN, J.; DEARDEN, J. (2018). A systematic review of English medium instruction in higher education. Cambridge University Press 2017.

MACIEL, R. F.; VERGARA, V. S. (2019). Internacionalização como prática local: um olhar situado sobre o papel da língua no English Club e no curso de Medicina. Organon Revista do Instituto de Letras da UFRGS, v. 34, n. 66. Disponível em: https://seer. ufrgs.br/organon/article/view/91066 Acesso em: 14 set. 2020. 
MARENGO, L. H. F; SARMENTO, S. (2019). Inglês como meio de instrução no ensino superior brasileiro: um estudo quantitativo e qualitativo de percepções de docentes. SALÃO DE INICIAÇÃO CIENTÍfICA, 31. UFRGS. Caderno de resumos [...]. Porto Alegre, RS. Disponível em: https://www.lume.ufrgs.br/handle/10183/208566 Acesso em: 28 jan. 2021.

MARTINEZ, R. (2016). English as a Medium of Instruction (EMI) in Brazilian higher education: challenges and opportunities. In: Finardi, K. R. (Ed.) English in Brazil: views, policies and programs. Londrina: Eduel, 193-228.

MARTINEZ, R.; FERNANDES, K. (2020). Development of a Teacher Training Course for English Medium Instruction for Higher Education Professors in Brazil. In: SÁNCHEZ-PÉREZ, M. M. (Org.). Advances in Higher Education and Professional Development. 1ed. IGI Global, p. 125-152.

MARTINEZ, R.; FOGAÇA, F.; FIGUEIREDO, E. H. D. (2019). An instrument for English Medium Instruction (EMI) classroom observation in higher education. Caderno de Letras, n. 35, p. 221-234, set-dez. Disponível em: https://periodicos. ufpel.edu.br/ojs2/index.php/cadernodeletras/article/view/17352/10998Acesso em: 10 fev. 2021.

MARTINEZ, R.; MORGAN, S. (2018). Is there a minimum level of English proficiency to teach in a university EMI context? UK-Brazil English Collaboration Call. British Council. Disponível em: https:/www.britishcouncil.org.br/sites/default/files/ uk_collaboration_call_-_martinezmorgan.pdf. Acesso em: 10 fev. 2021.

MATHEUS, M. C. C. (2009). Metassíntese qualitativa: desenvolvimento e contribuições para a prática baseada em evidências. Acta, São Paulo, v. 22, p. 543-545.

MOORE, P.; FINARDI, K. R. (2020). The role of English and internationalization in the South... of the North. In: FINARDI, K. R (ed). English in the South. Londrina, PR: Eduel. p. 267-293.

MURATA, K. (ed.). (2018). English-Medium Instruction from an English as a Lingua Franca perspective - exploring the bigher education context. Abingdon: Routledge.

OLIVEIRA, L. F. de. (2016). O que é uma educação decolonial? Revista Nuevamérica, n. 149, p. 35-39. Disponível em: < http:// www.novamerica.org.br/ong/?p=1230>. Acesso em: 5 abr. 2021.

PALSRUD, B. A.; TIAN, J. (2021). English-Medium Instruction and Translanguaging. Multilingual Matters.

PARK, J. S; WEE, L. (2012). Markets of English: linguistic capital and language policy in a globalizing world. New York: London Routledge.

PENNYCOOK, A. (2000). English, politics, ideology: From colonial celebration to postcolonial performativity. In: Ideology, politics, and language policies: Focus on English, ed. T. Ricento, Amsterdam, The Netherlands: John Benjamins.

RIOS-REGISTRO, E. S.; MOSS, H.; SCHMITT, L. G. (2018). EMI training for university professors: a potential tool for internationalization. UK-Brazil English Collaboration Call. British Council. Disponível em: https://www.britishcouncil.org.br/ sites/default/files/uk_collaboration_call___registromoss.pdf. Acesso em: 10 fev. 2021.

ROBERTS, P.; ARKHIPENKA, V.; LANVERS, U.; LUNYOVA, T. (2019). I have completely changed my point of view concerning native speakers: An EMI training project promoting emancipatory pedagogy. ELT Research Papers. London: British Council.

RODRIGUES, B. G.; ROCHA, A. O. (2020). Reflecting about the challenge of using English as a Medium of Instruction in Piaui. In: Richter, Carla Lima; Nóbrega, Daniela Gomes; Souza, Fábio Araújo Marques, do Nascimento, Juscelino Francisco (orgs). Language teaching -learning in the 21st century. São Paulo: Mentes Abertas, p. 119-128.

SARMENTO, S.; BAUMVOL, L. (2019b). Practices of EMI in Brazil: a mixed-method analysis. FAUBAI 2019 Conference Global Community Engagement. Belém: Brasil.

STALLIVIERI, L.; GONÇALVES, R. B. (2015). Novas propostas pedagógicas para o desenvolvimento de disciplinas ministradas em línguas estrangeiras das salas de aula multiculturais. Revista de ciências da Administração, v. 17, n. 41, p. 130-142. 
TAQUINI, R. (2020). Internacionalização = EMI? Evidências do inglês na UFES. Dissertação de Mestrado em Educação e Linguagens. Universidade Federal do Espírito Santo, UFES, Vitória.

VAVRUS, F.; PEKOL, A. (2005). Critical internationalization: moving from theory to practice. FIRE: Forum for International Research in Education. Disponível em: https://preserve.lib.lehigh.edu/islandora/object/preserve\%3Abp-6304021. Acesso em: 27 jan. 2021.

VERDU, F. C. (2017). EMI (English as a Medium of Instruction) como estratégia de internacionalização em casa: um estudo de caso num programa de pós-graduação em administração. In: EnANPAD 2017, São Paulo. Anais [...]. São Paulo: ANPAD. p. 1-8. Disponível em: https://www.researchgate.net/publication/319910377_EMI_ENGLISH_AS_A_MEDIUM_OF_ INSTRUCTION_COMO_ESTRATEGIA_DE_INTERNACIONALIZACAO_EM_CASA_UM_ESTUDO_DE_ CASO_NUM_PROGRAMA_DE_POS-GRADUACAO_EM_ADMINISTRACAO.Acesso em: 10 fev. 2021.

VOSGERAU, D. S. R.; ROMANOWSKI, J. P. (2014). Estudos de revisão: implicações conceituais e metodológicas. Revista Diálogo Educacional, Curitiba, v. 14, n. 41, p. 165-189, jan-abr.

WÄTCHER, B. (2000). Internationalisation at home - the context. In: CROWTHER, P., JORIS, M., OTTEN, M., NILSSON, B. \& WÄTCHER, B. Internationalisation at bome: A position paper. Amsterdam: European Association for International Education (EAIE), p. 1-46.

ZÜGE, A.; BARRETO, A.; NOVELLI, J. (2020). EMI em foco: percepções, possibilidades e desafios. Revista NUPEM, Campo Mourão, v. 12, n. 26, p. 43-61. 
APÊNDICE A

\begin{tabular}{|l|l|}
\hline Orientadores(as) & Pós-graduandos(as) \\
\hline & $\begin{array}{l}\text { MARIZA TULIO. O ensino por meio de inglês (EMI) no ensino superior no contexto } \\
\text { pós-Pandemia-Covid-19. Início: 2019. Tese (Doutorado em Letras) - Universidade } \\
\text { Federal do Paraná. (Orientador). }\end{array}$ \\
\hline FÁBIA CARLA ROSSONI. Inglês como Meio de Instrução no Ensino Superior: Uma \\
comparação entre universidades particulares e públicas. Início: 2019. Tese (Doutorado \\
em Letras) - Universidade Federal do Paraná. (Orientador).
\end{tabular}

Recebido: 23/3/2021

Aceito: 10/6/2021

Publicado: 17/6/2021 